\title{
The Effect of Heating on the Anticorrosive Self Assembled Phosphonic Acid Nanolayers
}

\author{
Éva Kocsisné Pfeifer ${ }^{1}$, Judit Telegdi ${ }^{2}$, István Gábor Gyurika ${ }^{1}$ \\ ${ }^{1}$ University of Pannonia, Institute of Material and Mechanical Engineering \\ 8200 Veszprém, Egyetem Str 10, Veszprém, Hungary \\ kocsisne.pfeifer.eva@mk.uni-pannon.hu; telegdi.judit@ttk.hu, \\ ${ }^{2}$ Department of Functional and Structural Materials, Institute of Materials and Environmental Chemistry, Research Centre \\ for Natural Sciences \\ 1117 Budapest, Magyar tudósok körútja 2, Hungary \\ gyurika@almos.uni-pannon.hu
}

\begin{abstract}
In order to decrease undesired corrosive reactions, special coatings, i.e. amphiphilic molecule in self-assembled nanolayers (SAM) formed from undecenyl phosphonic acid was applied on carbon steel surface. The amphiphile has double bond at the end of the medium size hydrophobic carbon chain, which offers the possibility of polymerization of molecules in SAM layer by different techniques. These post-treatment process by UV light and by heating increase the compactness of the nanolayer, and alter the surface film into a net-like structure on the metal. The nanolayers are characterized by measuring the water wettability, and by surface visualizing method as well as by infrared reflection absorption spectroscopy. The anticorrosion efficiency was visualized by atomic force microscopy.
\end{abstract}

Keywords: Self-assembled nanolayers, Undecenyl phosphonic acid, Post-treatment, Carbon steel, anticorrosion effect.

\section{Introduction}

The corrosive deterioration of metals causes significant loss of materials and costs a lot every year. The corrosion, a thermodynamically spontaneous process occurs always when a metal comes in contact with water or its vapor (especially when electrolytes and corrosive materials are present). The material loss of metals is due to redox processes.

The types of the corrosions are the follows: 1.chemical corrosion (a direct contact is necessary between the metal and the aggressive environment), 2. electrochemical corrosion (in this case the oxidation (anodic) and the reduction (cathodic) reactions are separated in presence of electrolyte that enables the charge transfer between the metal and the corrosive environment) and 3. microbiologically influenced corrosion (which is caused by corrosion-relevant microorganisms). The most frequently occurring corrosion type is the electrochemical one. In all cases the presence of water is indispensable that makes possible the charge transfer at the metal-solvent interface. These processes are represented by the follow equations (1) - (2):

$$
\begin{gathered}
\mathrm{Me} \rightarrow \mathrm{Me}^{\mathrm{n}+}+\mathrm{ne}^{-} \\
\mathrm{Ox}+\mathrm{ne}^{-} \rightarrow \text { Red }
\end{gathered}
$$

In electrochemical corrosion mainly the oxygen is responsible for the corrosive attack. It accepts the electrons that are released by the metal as shown in Eqs. (3) - (4):

$$
\begin{gathered}
2 \mathrm{H}^{+}+2 \mathrm{e}^{-} \rightarrow \mathrm{H}_{2} \\
\mathrm{O}_{2}+2 \mathrm{H}_{2} \mathrm{O}+4 \mathrm{e}^{-} \rightarrow 4 \mathrm{OH}^{-}
\end{gathered}
$$


The appearance of the corrosion could be very different (general corrosion: almost the most part of the surface is damaged; pitting corrosion: there are holes on the surface, their depth is much longer than the opening; crevice/intergranular/stress corrosion, microbial corrosion, etc.). The factors that influence the type and severity of the damaging processes are the concentration of the corrosive compounds, the temperature, the $\mathrm{pH}$ as well as the type of the metals, the heterogeneity of their surface, and the roughness.

In order to decrease the corrosion there are several possibilities. Inhibitors are used most frequently as dissolved additives in an aqueous/oily environment; these inhibitor molecules contain special heteroatoms like oxygen, nitrogen, phosphorous, sulfur atoms that increase the anticorrosion efficacy [1-4]. Among these big groups of molecules the phosphonic acid derivatives play important role [5,6] as their anticorrosion activity in some cases are close to the chromate's activity, but that one is already banned because of its toxicity.

Another possibility for controlling the corrosion is the application of surface coating. The thickness of coatings could be macroscopic like in the case of paints; but also very thin (when only one or several molecular layers cover the metal surface). These thin layers can effectively control the corrosion. Our work was focused on the application of molecular layers prepared by self-assemble technique. The advantage of this preparation method is its simplicity. This technique allows the design and fabrication of nanostructured systems [7-10].

The research discussed here is based on results achieved in our laboratory [11-17]. The main line of our research was to improve the nanolayer effectiveness by cross linking the molecules that form the SAM layer to achieve the most compact self-assembled monolayers and characterize them before and after post-treatment by special methods [18]. We want to show the differences in the layer structure/composition depending on the formation conditions by applying different techniques: tensiometer, scanning probe microscopy, and special infrared spectroscopy.

Polarization modulation infrared reflection absorption spectroscopy (PM-IRRAS) has applied for many years successfully to the study of nanolayers absorbed on metal surfaces. It is an especially simple and nondestructive way to get molecular information on bidimensional systems, such as the formation of chemical bonds with the solid substrate, the conformation of the amphiphile molecules, and the orientation of the functional groups.

\section{Experiments}

In this section the materials used all along these experiments as well as the techniques applied for nanolayer preparation and characterization are described. All experiments were carried out at room temperature, except the heating of the metal coupon with SAM layer. The conditions of measurement are described at the different techniques.

\subsection{Materials}

Metal: Carbon steel (composition: C: 2.29\%; Fe: 97.71\%)

Amphiphile: undecenyl phosphonic acid $\left(\mathrm{CH}=\mathrm{CH}-[\mathrm{CH} 2]_{9}-\mathrm{PO}(\mathrm{OH})_{2}, \mathrm{MW}: 234\right)$, (Specific Polymers, Castries, France).

\subsection{SAM layer preparation}

The undecenyl phosphonic acid was dissolved in organic solvent (methanol) at the concentration $5 \times 10^{-3} \mathrm{M}$. The metal samples (10x10x2mm), after polishing (first with emery paper (200,400, 800 and 1200 mesh), then by diamond past (1512-9-6-3 $\mu \mathrm{m}$ grain size) were dipped into the amphiphile's solution and kept in it for different intervals. After pulling out the coupons, the superfluous solvent was removed in methanol and the metal was dried at air.

\subsection{Post-treatment of the layers}

by UV-illumination $(\lambda=254 \mathrm{~nm}), 60 \mathrm{~min}$

by heat-treatment (the SAM-covered metal samples were kept at $80^{\circ} \mathrm{C}$ in an oven) 


\subsection{Water wettability measurements}

The bare and pre-coated samples were characterized by dynamic contact angle values measured in MilliQwater (tensiometer: DST 9005 NIMA Ltd, the depth of immersion: 8mm, the dipping speed: $5 \mathrm{~mm} / \mathrm{min}$ ) [15]. All measurements were repeated three times. In all cases the error of the measurements was less than $1 \%$.

\subsection{AFM measurements}

The SAM layers before and after the post-treatment and corrosion attack were visualized by atomic force microscope (NanoScope III, Digital Instrument, contact mode, tip: $\mathrm{Si}_{3} \mathrm{~N}_{4}$ ) measuring and visualizing the change on the surfaces. The roughness parameters were calculated by the instrument's software. The surface roughness was checked at least on three different images taken at the same $\mathrm{x}$ and $\mathrm{y}$ size. The error was always less than $1 \%$.

\section{Results and discussion}

In 1946 was first published the preparation of self-assembly of a surfactant onto a metal. This is an easy and low-cost fabrication method. The amphiphilic molecules (consist of small head group and long hydrophobic chain) can adhere to a solid surface with their head groups. These bonds could be ionic interaction, covalent bond, complex formation; according to the force they can form by chemisorption or by physisorption. The hydrophobic molecular part is kept together by different forces. Weak non-covalent bonds play the key role in self-assembly such as van der Waals forces, hydrogen bonds (a special type of the dipole-dipole interaction, which is stronger than the van der Waals force) and $\pi$ - $\pi$ interactions. Another week force that keeps together the hydrophobic molecular part in the nanolayer is the hydrophobic interaction [1922].

It is well-known that the phosphonic head-groups adhere to the oxide layer of a meal surface. Tridentate bonds are formed because of hydrogen bond formation between the phosphoryl oxygen and the surface hydroxyl group [23, 24]. The hydrophobic alkyl/alkenyl chains contribute to intensification of the SAM layer structure. The wettability results of the undecenyl phosphonic acid SAM nanolayers before and after UV treatment showed that the compactness of the layer increases not only with the increase in the amphiphile concentration, but with the compactness of the organic nanolayer caused by the polymerization of the double bonds at the end of the alkyl chain (the water contact angles are higher (Table 1). This modification could enhance the flexibility of the SAM layer and allow the formation of special functional surfaces that could be more proper e.g. for tribological purpose or for anticorrosion protection [25].

Table 1: Water wettability of the carbon steel coupons covered by undecenyl phosphonic acid SAM layers; influence of the concentration and the post-treatment via UV light illumination (concentration of the amphiphile: $10^{-3} \mathrm{M}$ and $10^{-2} \mathrm{M}$; illumination: 60 $\min$ at $374 \mathrm{~nm})$.

\begin{tabular}{|c|c|c|}
\hline $\begin{array}{c}\text { Concentration of the } \\
\text { amphiphile }\end{array}$ & $\begin{array}{c}\text { Formation time of the } \\
\text { nanolayer }\end{array}$ & Contact angle \\
\hline $10^{-3} \mathrm{M}$ & $12 \mathrm{~h}$ & $102.2^{\circ} \pm 0.5^{\circ}$ \\
\hline $10^{-2} \mathrm{M}$ & $12 \mathrm{~h}$ & $105.3^{\circ} \pm 0.3^{\circ}$ \\
\hline $10^{-3} \mathrm{M}$ & $12 \mathrm{~h}+\mathrm{UV}$ light & $107.2^{\circ} \pm 0.6^{\circ}$ \\
\hline
\end{tabular}

We tried to increase the compactness of the SAM layer of undecenyl phosphonic acid by heat treatment. The layer compactness before the treatment and after surface modification was characterized by contact angle measurements (Table 2). According to the contact angle data the wettability of the SAM layer after heat treatment did not change so significantly than after the UV handling. It means that the structure of the layer was altered but less than in case of the intermolecular covalent interaction (resulted by UV handling. It is clear that a covalent bonding produces a more compact layer that improves more effectively the resistance of this nanolayer. The work, which will show the real impact of the temperature on the layer, continues. 
Table 2: Influence of the heat post-treatment on the water wettability measured on carbon steel coupons covered by undecenyl phosphonic acid SAM layers; (SAM layer formation time $12 \mathrm{~h}$ at $10^{-3} \mathrm{M}$ concentration; heat treatment: $3 \mathrm{~h}$ and $5 \mathrm{~h}$ at $80{ }^{\circ} \mathrm{C}$ ).

\begin{tabular}{|c|c|c|}
\hline $\begin{array}{c}\text { Concentration of the } \\
\text { amphiphile }\end{array}$ & $\begin{array}{c}\text { Heat treatment time of the } \\
\text { nanolayer }\end{array}$ & Contact angle \\
\hline $10^{-3} \mathrm{M}$ & $0 \mathrm{~h}$ & $102.2^{\circ} \pm 0.5^{\circ}$ \\
\hline $10^{-3} \mathrm{M}$ & $3 \mathrm{~h}$ & $102.8^{\circ} \pm 0.4^{\mathrm{o}}$ \\
\hline $10^{-3} \mathrm{M}$ & $5 \mathrm{~h}$ & $103.5^{\circ} \pm 0.5^{\circ}$ \\
\hline
\end{tabular}

The anticorrosive efficacy was followed by atomic force microscopy. It was shown that the undecenyl phosphonic acid SAM layer was less compact than that one handled by UV light. It was reflected in the increased surface roughness (Table 3).

Table 3: Change in the $\mathrm{R}_{\max }$ roughness parameters (derived from the AFM images) caused by the SAM deposition, by illumination by UV light (for $60 \mathrm{~min}$ ) and by $\mathrm{NaCl}$ treatment.

\begin{tabular}{|c|c|c|}
\hline Sample & $\mathbf{R}_{\max }[\mathbf{n m}]$ & $\begin{array}{c}R_{\max }[\mathrm{nm}] \text { after } 1 \mathrm{~h} \mathrm{NaCl} \\
\text { treatment }\end{array}$ \\
\hline bare metal & $53.1 \pm 0.1$ & $644 \pm 4$ \\
\hline $\begin{array}{l}\text { +undecenyl phosphonic acid } \\
\text { SAM layer }\end{array}$ & $40.4 \pm 0.2$ & $472 \pm 3$ \\
\hline $\begin{array}{l}\text { +undecenyl phosphonic acid } \\
\text { SAM layer+UV treatment }\end{array}$ & $29.2 \pm 0.2$ & $245 \pm 4$ \\
\hline
\end{tabular}

Important observation is that the SAM layer was more compact after UV treatment (reflected in data of Table 3). As the AFM images in Figure 1 show the bare metal surface is much rougher than the SAM layer covered metal and the sodium chloride could deteriorate the bare metal more seriously than that one which was previously covered by SAM layer. Additionally, when the SAM layer covers the metal surface, the chloride ions could not penetrate easily into the layer, cannot influence the metal dissolution and so can it control the pit formation i.e. the pitting corrosion (Figure 1).

The roughness values support the visual inspection of the AFM images taken on the sodium chloride affected bare metal surfaces as well as on the SAM layer covered metals. In the presence of the molecular layer the chloride ions could not deteriorate significantly the solid surface. 

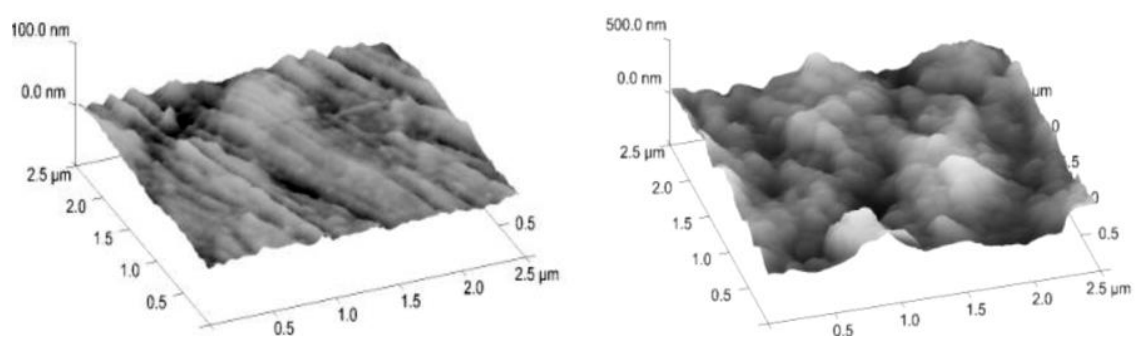

a

b

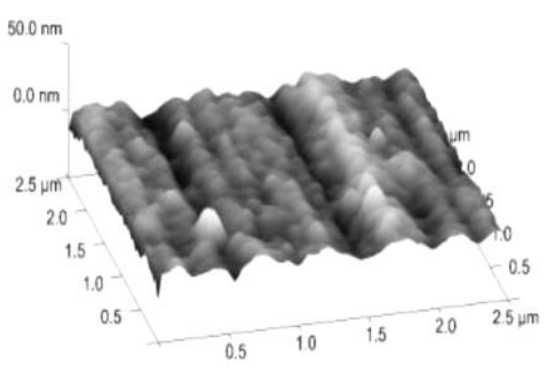

c

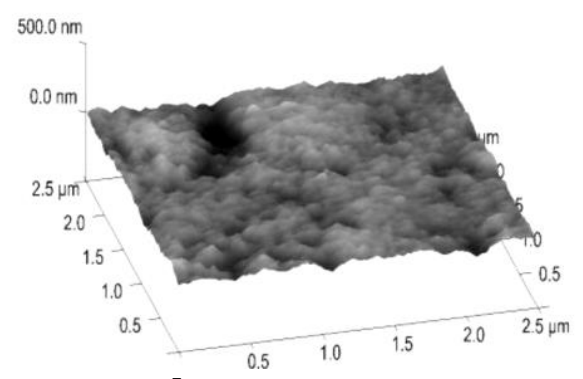

d

Fig. 1: AFM images of sample surfaces; a: bare metal, b: bare metals surface after immersion in 3,0 m/m\% NaCl solution for $1 \mathrm{~h}$; c: bare metal covered by undecenyl phospohonic acid SAM layer; $\mathbf{d}$ : the undecenyl phosphonic acid SAM layer-covered carbon steel surface after immersion into $3,0 \mathrm{~m} / \mathrm{m} \% \mathrm{NaCl}$ solution for $1 \mathrm{~h}$ [11].

The study of the self-assembled monolayers before and after post-treatments by infrared reflection absorption spectroscopy (IRRAS) started that will show the differences in the nanolayer structure caused by the different treatments.

\section{Summary and Conclusion}

We demonstrated the usefulness of self-assembled nanolayers of undecenyl phoshonic acid amphiphilic molecule in metal surface modification in order to control the undesired corrosion processes. The positive effects of the nanolayers are reflected in the decreased water permeability that revealed itself in the increased water contact angle values. The double bond at the end of the alkenyl chain allowed the polymerization via post-treatment that improved the compactness of the nanolayer. The influence of the UV light allowed polymerization of the double bonds and the result was a more compact molecular film. This densely packed structure is responsible for the more effective anticorrosion efficiency as was demonstrated in the case of pitting corrosion.

\section{Acknowledgements}

I wish to express my gratitude to Tala Abohalkuma at the Libyan Petroleum Institute for her help in sample preparation and contact angle measurements.

\section{References}

[1] Y. I. Kuznetsov, A. A. Chirkunov, A. S. Gorbachev, and N. P. Andreeva, "Passivation of mild steel by sodium octylphosphonate in neutral aqueous solution,” Int. J. Corros. Scale Inhib., vol. 6, no. 3, pp. 318-332, 2017.

[2] Y. I. Kuznetsov, "Organic corrosion inhibitors: Where are we now? A review. Part IV. Passivation and the role of mono- and diphosphonates," Int. J. Corros. Scale Inhib., vol. 6, no. 4, pp. 384-427, 2017.

[3] M. O. Abdulazeez, A. K. Oyebamiji, and B. Semire, "DFT-QSAR studies on corrosion inhibition efficiency of derivatives of thiadiazole, oxadiazole and triazole," Int. J. Corros. Scale Inhib., vol. 5, no. 3, pp. 248-262, 2016.

[4] P. B. Raja, M. Ismail, S. Ghoreishiamiri, J. Mirza, M. C. Ismail, S. Kakooei, and A. A. Rahim, "Reviews on Corrosion Inhibitors: A Short View," Chem. Eng. Commun., vol. 203, no. 9, pp. 1145-1156, 2016. 
[5] X. H. To, N. Pebere, N. Pelaprat, B. Boutevin, and Y. Hervaud, "A corrosion-protective film formed on a carbon steel by an organic phosphonate," Corros. Sci., vol. 39, no. 10-11, pp. 1925-1934, 1997.

[6] A. Paszternák, S. Stichleutner, I. Felhősi, Zs. Keresztes, F. Nagy, E. Kuzmann, A. Vértes, Z. Homonnay, G. Pető, and E. Kálmán., "Surface modification of passive iron by alkyl-phosphonic acid layers," Electrochim. Acta, vol. 53, no. 2, pp. 337-345, 2007.

[7] J.-M. Lehn, Supramolecular Chemistry, Weinheim, Germany, WILEY-VCH Verlag GmbH, 1995.

[8] P. Gale, J. Steed, Supramolecular Chemistry: From Molecules to Nanomaterials; Weinheim, Germany,WileyVCH, Verlag GmbH \& Co. KgaA, 2012.

[9] D. Lombardo, P. Calandra, L. Pasqua, and S. Magazù, "Self-assembly of organic nanomaterials and biomaterials: The bottom-up approach for functional nanostructures formation and advanced applications," Materials (Basel)., vol. 13, no. 5, pp. 1-43, 2020.

[10] A. Tiwari, Nanomaterials in Drug Delivery, Imaging, and Tissue Engineering, Weinheim, Germany, Wiley-VCH Verlag GmbH \& Co. KGaA, 2013.

[11] J. Telegdi, T. Abohalkuma, "Influence of the nanolayer' post-treatment on the anticorrosion activity," Int. J. Corros. Scale Inhib., vol. 7, no. 3, pp. 352-365, 2018.

[12] J. Telegdi, G. Luciano, S. Mahanty, T. Abohalkuma, "Inhibition of aluminum alloy corrosion in electrolytes by selfassembled fluorophosphonic acid molecular layer," Mater. Corros., vol. 67, no. 10, pp. 1027-1033, 2016.

[13] T. Abohalkuma, A. Shaban, J. Telegdi, "Corrosion processes controlled by phosphonic acid nano-layers," Period. Polytech. Chem. Eng., vol. 60, no. 3, pp. 165-168, 2016.

[14] T. Abohalkuma, J. Telegdi,"Corrosion protection of carbon steel by special phosphonic acid nano-layers," Materials and Corrosion, vol. 66, no. 12, pp. 1382-1390, 2015.

[15] T. Abohalkuma, F. Shawish and J. Telegdi., "Phosphonic acid derivatives used in self assembled layers against metal corrosion," Int. J. Corros. Scale Inhib., vol. 3, no. 3, pp. 151-159, 2014.

[16] J. Telegdi, T. Rigó, É. Pfeifer, T. Keszthelyi, E. Kálmán, "Nanolayer coatings," Progr. Colloid Polym. Sci. vol. 135, pp. 77-86, 2008.

[17] J. Telegdi, T. Rigó, E. Kálmán, "Molecular layers of hydroxamic acids in copper corrosion inhibition," $J$. Electroanal. Chem., vol. 582, no. 1-2, pp. 191-201, 2005.

[18] L. Xiao, Z. D. Schultz, "Spectroscopic Imaging at the Nanoscale: Technologies and Recent Applications," Anal. Chem., vol. 90, no. 1, pp. 440-458, 2018.

[19] K. J. M. Bishop, C. E. Wilmer, S. Soh, and B. A. Grzybowski, "Nanoscale forces and their uses in self-assembly," Small, vol. 5, no. 14, pp. 1600-1630, 2009.

[20] C.G.Claessens, J.F. Stoddart," $\pi-\pi$ interactions in self-assembly," J. Phys. Org. Chem., vol. 10, no. 5, pp. 254-272, 1997.

[21] M. J. Krische, J.-M. Lehn, "The Utilization of Persistent H-Bonding Motifs in the Self-Assembly of Supramolecular Architectures," vol. 96, pp. 3-29, 2000.

[22] D. C. Sherrington, K. A. Taskinen, "Self-assembly in synthetic macromolecular systems via multiple hydrogen bonding interactions," Chem. Soc. Rev., vol. 30, no. 2, pp. 83-93, 2001.

[23] T. Nakamoto, M. Katada, K. Endo, and H. Sano, "Structure of Fe3O complexes with long alkyl chain fatty acid, $[\mathrm{Fe} 3 \mathrm{O}(\mathrm{O} 2 \mathrm{CCnH} 2 \mathrm{n}+1) 6 \mathrm{~L}$ 3] NO3 $(\mathrm{L}=\mathrm{H} 2 \mathrm{O}, \mathrm{n}=11,13,15,17 ; \mathrm{L}=\mathrm{py}, \mathrm{n}=13,15,17)$; Crystal structure of [Fe3O(O2CC13H27) 6(py)3]NO3," Polyhedron, vol. 17, no. 20, pp. 3507-3514, 1998.

[24] S. Valiyaveettil, V. Enkelmann, K. Müllen, "Supramolecular structures formed from hydrogen-bonded networks of 5-alkoxyisophthalic acid,” J. Chem. Soc. Chem. Commun., no. 18, pp. 2097-2098, 1994.

[25] A. Dhotel, Z. Chen, L. Delbreilh, B. Youssef, J. M. Saiter, and L. Tan, "Molecular motions in functional selfassembled nanostructures," Int. J. Mol. Sci., vol. 14, no. 2, pp. 2303-2333, 2013. 